\title{
The current landscape at the University of \\ Edinburgh
}

Judy Robertson

The University of Edinburgh is situated in the capital city of Scotland, which is known variously as the Athens of the North, birthplace of the Enlightenment, British Entrepreneurial City of the Year ' , and Auld Reekie. The University, established in 1583, is a community of around 50,000 people. It has a wide global reach; it is ranked at 23 rd in an international rating of world universities ${ }^{2}$, and has alumni in 200 countries across the world. Nobel laureates from the University include Peter Higgs, Winston Churchill and Alexander Fleming. Charles Darwin, David Hume and James Hutton all studied here. It is the only (known) institution at which the Principal of the University hits graduates over the head with a medieval space bonnet ${ }^{3}$, and even our Library Cat publishes books ${ }^{4}$.

The alert reader may spot that the historical figures typically associated with the University (and even Library Cat) are male. To be fair, this is partly because of historical bias we are more likely to have heard of male intellectuals of previous times because women were until recently denied opportunities in almost any sphere outside the home. Relatively speaking, the University of Edinburgh was forward thinking in admitting the first women undergraduates to any British University in 1869. The University (and the Scottish patriarchy) appears to have mucked this one up to my 
untrained historical eye - after the women were admitted, there was a riot, scholarship skulduggery, court battles, graduation denials and then the final insult of dematriculations. The first women eventually graduated from the University in $1893^{5}$.

Happily, we have come a long way in our quest for gender equality. Now around $60 \%$ of our students are women, and $42 \%$ of our academic staff. Women alumni and honorary graduates are celebrated by the University ${ }^{6,7}$ including Gabi Hegerl who was part of an international team of climate scientists which won a Nobel Peace Prize; the pioneering surgeon Gerturde Herzfield, the chemist Christina Cruikshank Miller, and honorary graduates: Malala Yousafzai (who then went on the become the youngest recipient of the Nobel Peace Prize), Anneila Sargant (NASA astronomer), and Julia Sebutinde (judge on the International Court of Justice). Dolly the sheep, the first cloned animal from an adult cell is also a famous University of Edinburgh female, although unlike Library Cat, she did not publish her memoirs. Progress has been made in appointing women to senior positions. In the 2016/17 academic year, the University Court is gender balanced and two out of three College heads are women. The Principal is male, one of the eight Vice Principals is a woman, as are twelve of twenty Assistant Principals.

In 2015, the University of Edinburgh received an Athena SWAN Silver award for gender equality ${ }^{8}$. It is one of only seven universities in the UK to hold this prestigious award, and the first in Scotland to achieve it. No university has been awarded a Gold institutional award to date.

Having read all the Athena submissions from the schools, and the University level award, I can tell you that gaining a Silver award is no mean feat. It requires sustained effort over a period of years - the Silver award came nine years after the institutional Bronze award from extremely committed individuals and teams, the wholehearted support of senior managers, and painstaking data collection at an institutional level. In a national evaluation of the Athena SWAN scheme, one Athena team lead likened the effort required in co-ordinating an Athena submission to writing a PhD thesis (Fox, 2014). There is no question that this University, individuals and the institution as a whole, has seriously invested in advancing gender equality, and has made considerable progress in doing so.

In spite of this progress, if someone asked me: "Do we study and work in a university where men and women are equally likely to succeed?", hand on heart I would have to say, "No". At Edinburgh, women are less likely to be promoted to the highest grades, are employed on more precarious contract types and receive less money for equivalent work (UoE, 2015). Men are less likely to study here, and those who do are less likely to achieve the highest degree classifications than their female counterparts (UoE, 2015). There is some indication that male students may be less satisfied with their experience at University than women students. In short, there is still work to be done, as described in the following article. I consider progress with respect to women staff, students and teaching, and then describe how progress has been achieved with reference to the action plans of Athena SWAN teams across the University.

\section{Staff}

When Darwin studied at the University of Edinburgh in 1825, there were no women academic staff. By 2014, 1623 of the 3875 academic staff were women 9 . I fondly imagine that if Darwin had had the good fortune to be taught by our illustrious women colleagues in our medical faculty now, he would not be under the misapprehension that women are intellectually inferior to men (Saini, 2017).

The University of Edinburgh didn't get around to appointing its first woman professor until $1958^{\circ}$, but there are 180 of us now. Today, while $42 \%$ of UoE academic staff are female, only $22 \%$ of the highest grade (Grade 10, professor level) are women

17 EqualBITE The current landscape at the University of Edinburgh 
(UoE, 2015). Perhaps this low figure is skewed by STEMM subjects (science, technology, engineering, medicine and mathematics) which we know have low proportions of women? In fact, the figures for STEMM subjects reflect those of the University as a whole: $40 \%$ of staff are female and $20 \%$ of grade 10 staff are female in our STEMM schools ". So while the humanities and social sciences may have better balanced gender profiles at entry level positions than the STEMM subjects, they too have significant gender barriers to address.

To put these figures in context, the proportion of women professors at Edinburgh is similar to the average across UK universities, although the proportion of female academic staff overall is slightly lower (the national average is $45 \%{ }^{12}$ ).

Even if women do make it to professor level, they face a pay gap: they receive on average $91 \%$ of the salary of a male professor. This is worth the non-trivial sum of $£ 6,609$ a year. The gender pay gap across all staff grades is $4 \%$ at Edinburgh: the average woman member of staff earns $£ 1,814$ a year less than the average male member of staff ${ }^{13}$.

Working conditions are also likely to be precarious for women, with more women in fixed term contracts or hourly contracts. Nationally, women are more likely to encounter job uncertainty, with a lower proportion of female academic staff on open ended/permanent contracts (5\% difference) ${ }^{14}$. In line with the national average, at the University of Edinburgh there is also a $5 \%$ difference, with $45 \%$ of female academic staff on fixed term contracts. The highest proportion of fixed term contracts occur at the lower end of the grade scale, and more women are employed on these grades than men.

The University of Edinburgh no longer uses 'hours to be notified' (zero-hours) contracts (in which the employee is not guaranteed to be given a minimum number of working hours). In 2013, the University reviewed its use of these contract types and moved staff to guaranteed-hours (GH) contracts (in which the employer is obligated to offer at least a guaranteed minimum number of hours over a given period, usually for the academic year); $21 \%$ of staff now have these contract types. In 2015/16, the proportion of women amongst staff on guaranteed hours contracts was $51.6 \%$ overall, although there was wide variation across disciplines ranging from $32.4 \%$ in the College of Science and Engineering to $71.2 \%$ in the College of Medicine and Veterinary Medicine ${ }^{15}$. The impact of guaranteed-hours contracts depends on an individual's circumstances. It can be stressful and economically difficult for staff who are trying to patch together a full-time salary from multiple $\mathrm{GH}$ contracts. For others, such as PhD students, it is beneficial because it gives them the flexibility to turn down work if they are busy with their studies (most of the GH contracts in the College of Science and Engineering are for student lab demonstrators in this position). It also enables the University to bring expertise from working professionals onto teaching programmes - for example from lawyers, doctors or teachers. Indeed, many of the $\mathrm{GH}$ contracts in the College of Medicine and Veterinary Medicine are doctors with specialist expertise required for guest teaching spots.

The University and College Union forecasts, based on the rate of progress in addressing the gender pay gap in the last decade, it will take until 2050 to close the gap. That's a long time, especially when the average shortfall is $£ 6,103$ per woman per year across the sector. That's an average loss of $£ 207,502$ for each woman over that time period ${ }^{16}$. The UCU's strike action in 2015 was partially in response to this issue.

The University of Edinburgh is committed to closing the gender pay gap (and addressing inequalities for other protected characteristics). Like other large employers in the UK, it is obliged to publish an equal pay audit report ${ }^{17}$. I encourage you to keep an eye on these figures as they are published, and firmly lobby your employer if it has not lived up to your expectations. 
In between reports, you can daydream about what you would do with $£ 207,502$.

\section{Students}

Let's consider student recruitment and attainment. Matters have improved since the University initially admitted seven women medical students 148 years ago. There are 37,861 students enrolled at the University at the time of writing ${ }^{18}$. Around $60 \%$ of undergraduate students at the University of Edinburgh are female, 54\% of postgraduate taught students and $45 \%$ of postgraduate research students.

At the University of Edinburgh, women students are considerably more likely to graduate with a first class or upper second degree. This is similar to the national picture, where $56 \%$ of students are female, and women outperform men in every subject apart from social studies ${ }^{19}$.

\section{Student satisfaction with teaching}

Teaching is one of the most important aspects of an academic's job, and as such, the University considers student evaluations of teaching (SET) carefully. However, there is research evidence to believe that in general students' evaluations of staff are gender-biased with female lecturers receiving harsher ratings (MacNell et al., 2014). Apparently some male students apply the same biases to their peers, as a recent study of biology students found that male students were inclined to overestimate the performance of their male peers while women did not exhibit this bias (Grunspan et al., 2016).

One source of data about student satisfaction is the National Student Survey (NSS) ${ }^{20}$ - a feature of university life in the UK which is guaranteed to make staff groan. All final year undergraduate students are invited (fairly insistently) to complete an online survey commissioned by HEFCE (the Higher Education Funding Council for England) and its counterparts elsewhere in the United Kingdom. The numerical results are then made publicly available ${ }^{21}$, and each institution receives a confidential copy of the free-text comments. This information is aggregated by national newspapers, along with other public data sets, to assist applicants and their parents to make choices about where and what to study. NSS consequently has a high profile, and a lot of energy is consumed by university managers in trying to improve scores. Currently gender data is not published by HEFCE but institutions can request it, as University of Edinburgh did this year.

On the question about overall student satisfaction, $82 \%$ of women students across the University agreed or strongly agreed that they were satisfied with their course, whereas only $76 \%$ of men did. It is difficult to interpret this finding without further investigation. Are men being discriminated against in the way we teach? Does this feed into men's comparative under-performance and the attainment gap noted above? Is the effect real or an artefact of the survey e.g. could women have been socialised into responding more favourably about their teachers? What underlying theory can account for such differences? Are there different patterns between disciplines? The patterns of answers to individual questions are intriguing - for example there are gender gaps in the students' responses to whether staff make the subject interesting and whether they are good at explaining. Given that we don't have gender apartheid in classes, where does this difference come from? Are women more generous in describing how interesting their lecturers are, or do lecturers make a special effort to be interesting in individual tutorial sessions with women students? Or do women just intrinsically find their subjects more interesting to begin with? A team at the University of Edinburgh will pursue answers to some of these questions in the coming year.

I was also interested to see whether there might be gender bias in student's perceptions of staff at the University of Edinburgh, so I decided to check the data from the Teaching Awards scheme to see

19 EqualBITE The current landscape at the University of Edinburgh 
if it might shed some light on the matter. Every year, the Edinburgh University Students Association (EUSA) organises a Teaching Awards scheme in which students nominate teaching and support staff who have made a difference to their learning, in categories such as best overall teacher, best dissertation supervisor, and best personal tutor. It's useful to consider this because: a) it is student-led and therefore might be said to reflect the views of those being taught on their own terms; b) staff promotion criteria are now based on evidence of teaching excellence, and teaching award nominations are regarded as a fair source for that evidence; and c) the awards are high profile. Alarmingly giant photos of the winners are displayed on public billboards all round campus. If those photos were all of men, it could perpetuate the bias that men are the brilliant teachers.

Information about the nomination and awards is shown in Table 1. The data is drawn from a report published by EUSA with additional information on teaching staff gender from HR (Human Resources). First of all, it's encouraging that so many students took the trouble to nominate their lecturers, and wrote so much in praise of their work. Secondly, it would appear that in 2015/16 there was not a gender bias in nominations as the gender breakdown in nominations is very close to the gender proportions of teaching staff. Either University of Edinburgh students are not biased in their evaluation of staff, or it doesn't manifest itself in award nominations for some reason. Either way, it is an important outcome because roughly equal numbers of giant male and female faces will beam down at us from billboards as beacons of teaching excellence.

Of course, the Teaching Awards data considers only evaluations relating to the excellent end of the spectrum. There may well be bias in the more routine evaluations of course lecturers - I invite lovers of data with time on their hands to take up the challenge to investigate this!

\section{Summary of Athena initiatives at the University of Edinburgh}

Athena SWAN is a charter of the Equality Challenge Unit which recognises higher education institutions which support "advancement of gender equality: representation, progression and success for all". The scheme started with a focus on the experiences of women students and academic staff in the STEMM disciplines, but since 2015 has been expanded to include arts, humanities, social sciences, business and law (AHSSBL) as well as professional services and support staff. The University of Edinburgh has been a founder member of Athena SWAN since its inception in 2005.

Currently 22 departments and schools within the University of Edinburgh hold Athena Awards at Silver or Bronze level. All Athena SWAN applications for the University can be found at ${ }^{22}$. After reading the Athena SWAN reports, and discussing more recent developments from the Athena SWAN teams by email and in meetings, I identified several common themes and approaches across submissions.

\begin{tabular}{|c|l|l|l|l|l|}
\hline $\begin{array}{c}\text { Teaching staff } \\
2014-2016\end{array}$ & \multicolumn{2}{|c|}{$\begin{array}{c}\text { Number of nominations by students of } \\
\text { their female and male teaching staff }\end{array}$} & Shortlisted & $\begin{array}{c}\text { Award } \\
\text { winners }\end{array}$ \\
\hline \multirow{2}{*}{ Female: $863(40 \%)$} & \multirow{2}{*}{$\begin{array}{c}2015 / 2016 \\
\text { Male: } 1301(60 \%)\end{array}$} & Female & $790(40 \%)$ & $10(40 \%)$ & $6(46 \%)$ \\
\cline { 3 - 6 } & \multirow{2}{*}{$2014 / 2015$} & Male & $1162(60 \%)$ & $15(52 \%)$ & $7(54 \%)$ \\
\cline { 3 - 6 } & & Female & $905(36 \%)$ & $12(57 \%)$ & $5(45 \%)$ \\
\hline
\end{tabular}

Table 1. EUSA teaching award nominations by gender 2014/15 and 2015/16 


\section{Financial commitment}

It is worth noting at the outset that some of the Silver award-holding departments have invested financially in their commitment to Athena SWAN. For example, the Roslin Institute, The Royal (Dick) School of Veterinary Studies and the Schools of Informatics and Economics have funds for childcare and conference travel to make it easier for those with young families to attend conferences and meetings. The Schools of Molecular, Genetic and Population Health Sciences, and Clinical Sciences offer funded fellowships for transition between career stages. For example, the Roslin Institute has invested in Career Track Fellowships (CTFs) which are timelimited training and career development positions designed to offer the opportunity to develop the skills and experience required to be eligible for appointment to Group Leader. They include funding for a research support position or PhD studentship, consumables budget and one internal and one external mentor. The Royal (Dick) School of Veterinary Studies has spent $£ 8,000$ in its Coaching for Success scheme.

\section{Keeping everyone informed}

The importance of keeping staff informed and up to date on equality and diversity news is a common theme. If the aim is to increase uptake of family-friendly flexible working policies, then staff need to know about it. As one of the Athena team leads told me, "The University can have some brilliant policies, but if no one knows about them or implements them, they are useless." Many of the schools with Athena awards maintain a Wiki with information relating to familyfriendly policies and other related material, or distribute it via email or social media. The Royal (Dick) School of Veterinary Studies keeps a "You said, we did" document on the intranet to inform staff of progress towards achieving goals suggested by staff. The School of Engineering also distributes paper copies of the University's Dignity and Respect policy in staff and student induction packs.

\section{Communication policies}

Athena SWAN has become integrated with standard school business. For example, in the School of Health in Social Science, the Athena SWAN team produces an annual progress report, there is an Athena SWAN section in the school plan, and it is a standing agenda item for the management committee. In addition, there is benefit to including at least one member of senior management on an equality and diversity committee (as in Engineering) or have section heads sit in on Athena SWAN meetings (Schools of Molecular, Genetic and Population Health Sciences, and Clinical Sciences). In the Schools of Mathematics and Engineering, updates on Athena SWAN issues are given at staff meetings. The scheduling of staff meetings is also important to enable those with caring responsibilities to attend. For example, Institute meetings are held in teaching weeks and not in school holidays at the Institute for Sport, Physical Education \& Health Sciences. It is also common to hold meetings in the middle of the day, and to rotate the day of the week on which events are held to avoid a situation in which people on flexible contracts can never attend.

In the schools and units with awards, great efforts have been made to keep Athena SWAN an ongoing topic of conversation. A team leader emphasised this as a key factor: "I think the central thing is communication. That is so important in raising awareness."

\section{Leadership}

Each Athena SWAN submission has an accompanying letter from the head of school (or unit). I have noticed that the content and tone of this letter really gives a clue as to what will follow in the report. Some letters reveal the strength of commitment from the head of school, their personal investment in making sure that change happens and their pride in what has already been achieved. For example, one head of school wrote a list of the initiatives which he personally had led or been part of and concluded:

21 EqualBITE The current landscape at the University of Edinburgh 
In summary, the implementation of strategies as part of our Athena SWAN agenda has had, and continues to have, my strongest support and commitment. We take pride in providing an outstanding student experience and a supportive work environment for all of our staff. I am incredibly proud that these efforts have been recognised in both student and staff surveys alike.

Other letters inadvertently gave me the impression that the author was performing a duty in writing it, rather than embracing the change process from personal conviction. The Athena SWAN leads commented on the importance of leadership in acting on data collected during the benchmarking process: "One thing that really helped with that was feedback to heads of centres on the findings from the [staff satisfaction] survey, [which was] conveyed in confidence by the heads of schools."

Other teams mentioned the role of leaders at various levels in the organisation in making new initiatives work:

...really key is leadership - we had two hugely supportive heads of school who were ready to push through the things we suggested and who supported our initiatives, including visibly by attending meetings. We also had a head of college with an 'open door' who was receptive to our initiatives, whilst not directly being involved (though he did appoint the two female heads of school and has gone on to recruit several other women to key leadership roles).

\section{Facilities}

\section{An effect of Athena SWAN nationally} has been to put the provision of familyfriendly facilities on universities' agendas. This is commonly in the provision of a breast feeding room and a fridge for storing expressed breast milk in order to support nursing mothers in their return to work. The Roslin Institute, for example, has dedicated facilities for baby changing, feeding, storing and heating milk. While it may be easy to allocate a room for breast feeding on paper, it requires more thought to make it comfortable and usable. Details such as where to get the key, whether it is used for only this purpose, whether it is quiet and clean and who has access to it make a difference to how successful it will be. It would be beneficial to have a map of the breastfeeding facilities available in each building of the campuses.

The University of Edinburgh recently opened a new nursery in the King's Buildings Science and Engineering campus, and (partly as a result of the Athena SWAN initiative) will invest $£ 2.3$ million in a new nursery for the more geographically remote Easter Bush campus in $2018^{23}$. Having access to high quality childcare on site makes a big difference to staff who are parents. It is worth noting that student parents also appreciate high quality childcare, and currently feel that their needs are not being adequately met ${ }^{24}$. In 2016, the Edinburgh University Students' Association passed a motion at Student Council to improve facilities for student parents, including calls for more co-ordinated support and advice for student parents, access to child-friendly facilities in all academic schools, affordable childcare and flexible provision in the University nursery, free transport for parents between all campuses and the nursery campus and a revision of the library policy which currently restricts access to the library to 30 minutes to those accompanied by children ${ }^{25}$. Personally I feel that the University libraries should make a point of actively welcoming children as part of its civic mission of sharing knowledge but then I am a professor of education, not a health and safety officer.

The Students' Association also passed a motion in 2015 pledging to offer at least one gender-neutral toilet in each building they manage which already offers toilet facilities (and the same for changing rooms) ${ }^{26}$, and later in the year updated this with the target of two-thirds of existing toilet facilities to be made gender-neutral ${ }^{27}$. Perhaps where the Students' Association 
leads, the University will follow. Some schools already have plans for introducing gender-neutral toilet facilities (e.g. the School of History, Classics \& Archaeology).

If you are interested in how buildings can be designed to promote a comfortable working environment for all, see Asking for equitable buildings by Derek Jones.

\section{Annual review}

As one of the main formal contact points between staff and their line managers, annual reviews (AR) have an important role in promoting and maintaining equality and improving work satisfaction. If you have worked as an academic, you may be inclined to roll your eyes at the words "annual review" or start muttering about "waste of time" - annual reviews sometimes do have a bad reputation among academics. Sometimes, I have noticed (at other institutions of course), older male academics might prefer not to have to bother with reviews because they believe they know what they're doing already. This may be why some schools, including Informatics, have been working on improving staff perceptions of annual review and training annual reviewers. The School of Biomedical Sciences runs reflective workshops for appraisers after the review cycle is complete.

Schools have also considered who conducts reviews - for example by introducing a choice of reviewer with at least one female on the review team (Economics), or ensuring that reviewers prioritise this task by mandating that an individual cannot be promoted if they have not completed their reviews of others (Chemistry). The topics for discussion at AR can also make a difference. The Schools of Molecular, Genetic and Population Health Sciences, and Clinical Sciences have cleverly changed the default position by rewording their AR forms: promotion and flexible working should both be routinely discussed at each review, and the reason for NOT doing this should be recorded if necessary. Across many schools, teaching and leadership and management are now routinely discussed and recorded during AR to show that all duties are valued; previously research may have dominated such meetings. In Economics the review also includes work-life balance.

\section{Promotions and career development}

One of the University's goals is to increase the proportion of women at senior lecturer, reader and professor levels. Data from across the University suggests that although more promotion applications come from men, those which do come from women have a higher success rate. There are potentially two problems here: men apply before they are ready, and women delay for too long in applying. In either case systematic consideration of all staff as to whether they have a promotion case would benefit both staff and employer. The default should switch from expecting staff to present themselves for promotion, to the school actively supporting staff to achieve it. In the Roslin Institute, the HR manager and head of school systematically consider all eligible academics, and in the School of Biomedical Sciences a promotion committee considers all staff. In the School of Chemistry, line managers encourage people to apply for promotion, and in the School of GeoSciences each staff $\mathrm{CV}$ is reviewed annually for strengths and weaknesses with respect to promotions and additional salary increments. It is also important to consider part-time staff for career development opportunities, rather than assuming that they will be unable to take on a new role. For further perspectives on promotion, see Proactive Promotion.

In Psychology, the gender balance for sabbatical leave applications is also monitored and care is taken to ensure adequate cover is provided during sabbatical leave to avoid overloading other staff.

Schools are also thinking about how to support development for early career staff which is important given the precarious nature of postdoctoral work. For example, the University has a talent register ${ }^{28}$ which is a first port of call for internal recruiters. Postdoctoral staff who are coming to the

23 EqualBITE The current landscape at the University of Edinburgh 
end of their contracts can sign up with the talent register to be considered for upcoming vacancies if they have the requisite skills. The School of Informatics has a portfolio manager to enable staff redeployment at the end of research contracts. The School of Chemistry is now focusing on postdoctoral career development. Postdoctoral staff can take the postgraduate certificate in academic practice course, get support in applying for fellowships, undergo appraisals, and are given opportunities to supervise students.

\section{Staff development}

The Athena submissions are very enthusiastic about mentoring, coaching and buddying. The University as a whole offers the Mentoring Connections scheme which matches staff who want some advice on work-life balance, career progression or promotion paths with volunteer mentors across the University ${ }^{29}$. The University also funds 20 women each year to attend the Aurora women's leadership development initiative which includes mentoring, and has successfully piloted a Returning Parents Coaching Scheme for those returning from maternity leave or shared parental leave to make an effective transition back to work ${ }^{30}$.

In the School of Mathematics, new staff are assigned a mentor for five years (as well as having a reduced teaching and administrative load in the first year to help them establish a research career). The Schools of Economics and History, Classics \& Archaeology, and The Royal (Dick) School of Veterinary Studies have a mentoring champion role for the purpose of matching staff with mentors and ensuring that mentors have adequate training. All junior academic staff in the School of History, Classics \& Archaeology have a research mentor. There are mentoring groups for career issues in the Schools of Molecular, Genetic and Population Health Sciences, and Clinical Sciences; in Biological Sciences there are mentors for all new principal investigators and mentoring for people going on maternity leave; the Roslin Institute and The Royal (Dick) School of Veterinary Studies have a parental leave mentoring scheme; and Divinity offers mentoring for PhD students.

Given all the effort which is devoted to mentoring programmes, it is worth bearing in mind Sheryl Sandberg's pithy comments on mentoring ${ }^{31}$. When reading most of her Lean In book, I was leaning back in incredulity about how very different her life is to mine, but she does have a point with the following suggestion: "Shift your thinking from 'If I get a mentor, I'll excel' to 'If I excel, I will get a mentor'". In my own role as research lead for my institute, I encourage staff to seek out flexible and fluid mentoring relationships to suit the area(s) of their career they wish to work on. I want staff to have a set of approachable people they can ask for advice when they need it, but I don't want them to feel unable to progress without outside help. I have also noticed that assigned formal mentor pairings can be problematic; sometimes taking advantage of more naturally occurring relationships can be effective.

Coaching is similar to mentoring in that they are both confidential, developmental conversations. Mentors are often people a few years ahead on a similar career path and mentoring relationships can be informal and can last for a long time. Coaches tend to have formal training in a range of coaching models and techniques and, as they are often external to the department or subject area, they can be more neutral sounding boards. Their expertise lies not in the details of an individual's field, but in the process of exploring and untangling complex problems to provide clarity and new perspectives. They can also provide support and accountability for people seeking to achieve their goals. The Institute 
for Academic Development offers coaching for staff ${ }^{32}$, as do various units including the Roslin Institute, the Business School and Informatics. You can read about a Roslin staff member's experiences in the recipe Career coaching for individuals. The Roslin Institute runs a coaching seminar for all line managers to assist them in conversations about promotion during annual reviews, while the head of school at The Royal (Dick) School of Veterinary Studies offers promotion coaching workshops for the heads of departments within the school. This head of school personally coaches women going through the promotion process. They also help all staff who have been unsuccessful in a promotion application to set objectives for the next two years. The Moray House School of Education has senior mentors who can provide support and guidance on the promotion process to junior colleagues which makes applying for promotion a more positive and enabling experience.

Schools have also focussed on specific training needs for staff in particular roles. For example, the Schools of Molecular, Genetic and Population Health Sciences, and Clinical Sciences have mandatory principal investigator training on managing research groups, and the School of Mathematics offers unconscious bias training for those involved in postgraduate recruitment.

\section{Parental leave}

In the United Kingdom, employees are entitled to shared parental leave and statutory shared parental pay after maternity leave for the first year of the baby's life. This means that the other parent, or the mother's spouse, civil partner or joint adopters can share in caring for the baby. The University of Edinburgh implements a more financially favourable version of this scheme ${ }^{33}$, although uptake is currently low.

In addition, the schools with Athena SWAN awards have developed processes to help parents make the transition between work and parental care. The tenure process for Chancellor's Fellows (the University of
Edinburgh's flagship scheme aimed at future research leaders) can be delayed due to parental leave. The Royal (Dick) School of Veterinary Studies has a checklist to help managers give the best support to women going on maternity leave and temporary staff are recruited for maternity leave cover (oddly this is not always the case in universities). Those at the Schools of Molecular, Genetic and Population Health Sciences, and Clinical Sciences can apply for technical support to enable them to generate key research data while on maternity leave. Staff returning to their posts after maternity leave have six months of release from teaching duties in the School of Biomedical Sciences, and in the School of GeoSciences care is taken to ensure that women return to teaching/admin duties with which they are already familiar to avoid a time-consuming learning curve. Here women are offered flexibility about whether they want to focus on their research when they return or prefer to ramp it up slowly.

Many staff members care for other family members (perhaps in addition to children). In recognition of this, the Schools of Molecular, Genetic and Population Health Sciences, and Clinical Sciences and The Royal (Dick) School of Veterinary Studies are piloting a Caring for Carers scheme.

\section{Flexible working}

Employees in the United Kingdom have a statutory right to request a flexible working arrangement, and the University of Edinburgh has many employees on flexible contracts. The University's flexible working policy is at 34 . I have had various flexible working arrangements (at two different universities) to help me with childcare arrangements $-100 \%$ compressed hours, $80 \%$ time and 90\% time. I have had colleagues who work part-time to enable them to manage health conditions or wind down until retirement. The great benefit to the department is that it retains skills and expertise of individuals who otherwise may choose to leave. This is worth the inconvenience of scheduling meetings with a team of people on different flexible hours. 
There can be a reality gap between a flexible contract on paper and the personal experience of trying to cope with an academic job on a flexible basis (see Flexible working: being realistic). The Athena SAWN award holder departments have worked on various ways to make flexible working more manageable. In Psychology, the Athena SWAN team is reviewing procedures for appropriately scaling down work for part-time staff. Various departments have a policy of scheduling meetings between 10am and $4 \mathrm{pm}$ to enable staff to do school drop-off and pick-up, or ensure that seminars are in the middle of the day. One problem with working part time is that routine admin tasks and meetings take up a higher proportion of your working time. So my personal favourite is the School of Health in Social Science's policy of having meeting-free periods each month to enable people to focus on teaching and research.

The good news is that these efforts appear to be working: in a major turn-around which helped the Royal (Dick) School of Veterinary Studies achieve their Silver award, staff now agree that they have a good worklife balance, which is partially attributable to a transparent workload model.

\section{Recruitment}

To move from an Athena Bronze to Silver award, a school or department must make progress in improving the proportion of women staff. This requires careful attention to recruitment practices.

\section{Part of the difficulty is to attract women} to apply for posts in the first place. Adverts often include a statement to welcome women applicants, and links to familyfriendly working policies. The School of Health in Social Science routinely advertises posts with a part-time/flexible option, and is piloting an option for job sharing. The School of Informatics offers relocation assistance for new hires to make it more attractive for international candidates. When using third-party recruitment companies for executive searches, the University requires diversity in the long list of candidates.
A strategy to address gender inequality is to ensure that people involved in recruiting staff or students are aware of the effects of unconscious bias, particularly those who chair panels. It is University policy that all those on recruitment and promotion panels have undergone unconscious bias training. After a request from the Schools of Molecular, Genetic and Population Health Sciences, and Clinical Sciences, the head of college made it mandatory for anyone recruiting staff to first attend a day of training about managing a research group. In addition, schools attend to the gender balance in interview panels in various ways. The School of Molecular, Genetic and Population Health Sciences, and Clinical Sciences found that their appointment success rate for women rose from $56 \%$ to $67 \%$ since they introduced the policy that a woman must be present on all interview panels for permanent jobs. Some schools have a regulation that interview panels should have at least $25 \%$ female and $25 \%$ male members, while others insist on a gender balance. To counter the problem with senior women getting overloaded with serving on interview panels, there is some effort to pool interviewers across colleges.

See the three recipes on Gender balancing staff recruitment for further suggestions about recruiting equitably, and questions about some of these practices.

\section{Committee work}

Athena SWAN shines a light on the proportion of women who serve on influential committees. When departments preparing a Bronze submission put all the data together, they commonly realise that the committees with more decision-making power (the management group) or prestige (the research committee) are dominated by men. Clearly shifting this balance benefits individual women in terms of promotion possibilities and the departments themselves in terms of using the full range of talent available. However, the drive towards ensuring that women are represented on important University committees can have the unintended consequence that senior 
women become overloaded with committee work and blink out of existence in a silent yawn. The Athena SWAN submissions have a variety of approaches to this. In the School of Divinity, for example, the senior management team can co-opt members to redress a gender imbalance if necessary. The School of Chemistry ensures that committee membership is covered in the workload model so that service is explicitly factored into working life and other work is reduced accordingly. Committee meetings are always held between 10am and 3pm. The Schools of Molecular, Genetic and Population Health Sciences, and Clinical Sciences have staggered terms for Athena SWAN team members. They factored succession planning into the committee from the outset to ensure there are more opportunities to be in a leadership role, and to prevent any one person from being over-burdened over a long time period. The School of Health in Social Science is experimenting with opening up opportunities for committee membership which don't require seniority (such as marketing and communications) and the Roslin Institute has a system where more senior staff can have delegated deputies on committees to offer opportunities and avoid committee overload.

\section{Students}

Athena SWAN should not just be about staff - we have a responsibility to create a supportive learning environment for students too. The award-holding departments have made some progress in this direction. For example, several schools have requirements about the gender balance of thesis committees, PhD students in Chemistry may request a female thesis advisor and the School of Mathematics makes sure both genders are represented in staff student liaison committees. In the School of Informatics, there is a policy never to put just one female student in a group (see Stereotype threat), and unconscious bias training for male students is offered during Innovative Learning week. Gender bias is also included in a third-year course on professional issues. The School of
GeoSciences reminds tutors to call on women students for answers as part of a tutor training course in direct response to comments in a student survey. In response to survey data from students, the School of Divinity also addresses equality and diversity in tutor training, covering legal and policy commitments, how to teach inclusively, how to model good behaviour and how to challenge inappropriate remarks or behaviour. It has made diversity a key part of postgraduate induction, with a 45-minute compulsory session encouraging students to think about what it means to be collegial and professional, as well as spelling out the University's Dignity and Respect policy and obligations regarding the Equality Act.

Athena SWAN benchmarking focuses more on arrangements for maternity leave for staff, rather than students. At the University of Edinburgh, full-time undergraduate and taught postgraduate students may apply to the Scottish Government means-tested childcare fund 35,36 , and a limited number of bursaries for the University nursery are available. PhD students funded by the RCUK are entitled to up to 26 weeks of maternity leave on full stipend and a further 26 weeks of unpaid maternity leave. In addition, the Schools of Molecular, Genetic and Population Health Sciences, and Clinical Sciences have negotiated six months of stipend for maternity leave for PhD students from the College of Medicine and Veterinary Medicine, regardless of funding source.

\section{Summary}

The gender landscape at the University of Edinburgh has changed slowly, but dramatically, since the fathers of the Enlightenment studied here. In the last decade in particular, staff and students at the University of Edinburgh have tirelessly worked to improve gender equality, as demonstrated by Athena SWAN recognition.

One benefit of participating in the Athena SWAN process is the requirement to gather benchmark data. The University now has a history of data, much of which

27 EqualBITE The current landscape at the University of Edinburgh 


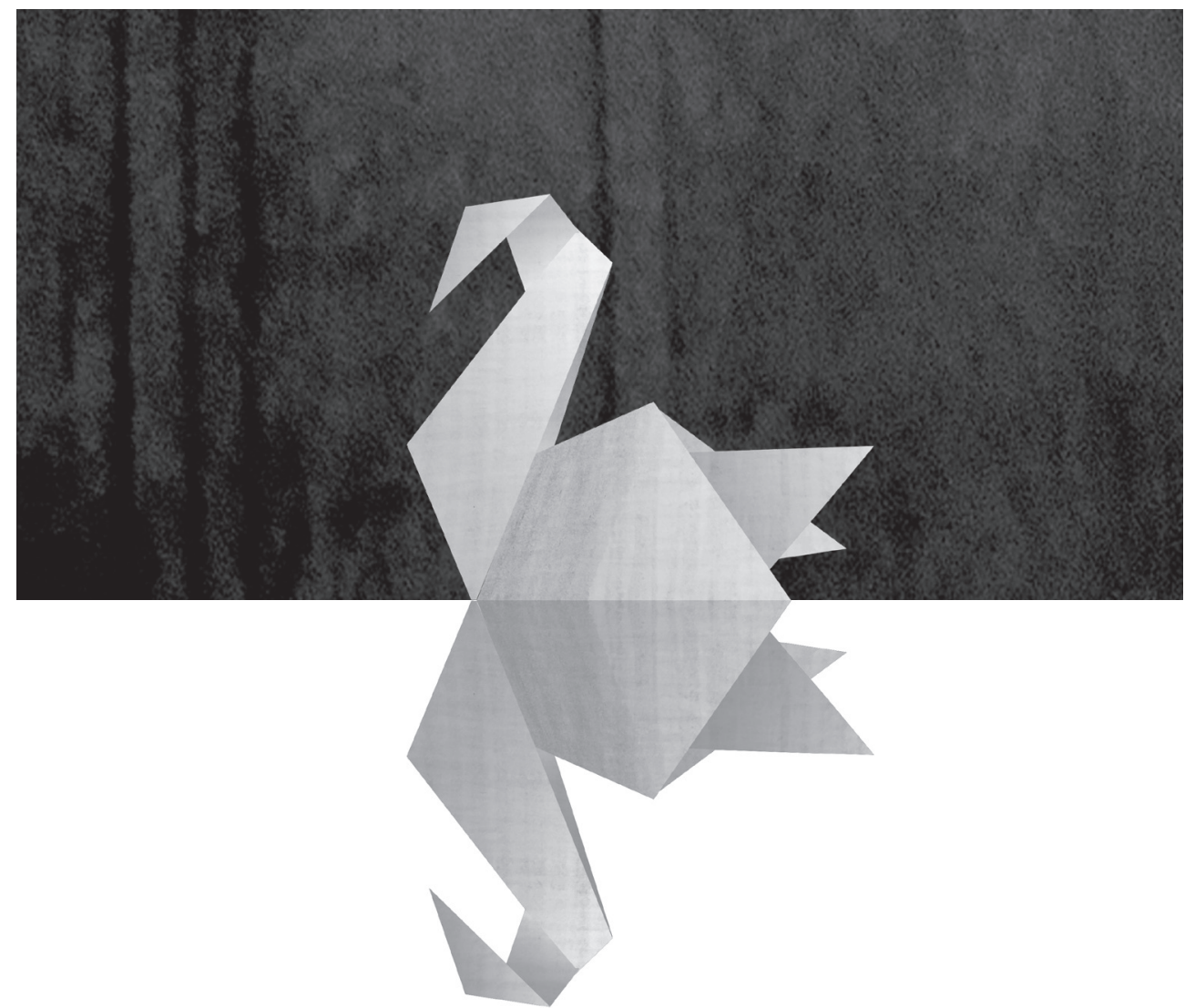

is publicly available, which combined with the data it must publish to comply with equality legislation, makes it comparatively easy to find answers to questions about how the status quo has changed. As Bohnet notes, benchmarking is an essential part of behavioural design for equality (Bohnet, 2016).

It is clear that the University has improved opportunities for women staff and students over the years, but that it cannot rest yet. In my view, tackling the gender inequalities relating to pay and the precariousness of working conditions needs further attention. The success of Athena SWAN initiatives could be usefully applied to addressing other inequalities concerning BME (black and minority ethnic) people, trans people and intersectionalities including social class and age.
It appears to me that Athena SWAN currently focuses more on the experience of staff rather than students. Obviously we have to start somewhere; ensuring that the people employed by an institution are not subject to gender inequality is a good beginning. As this aspect improves, I believe that we should put effort into ensuring that student experience and attainment is not subject to gender inequalities - either to the detriment of men at undergraduate level or women in some postgraduate courses.

The University has an opportunity and responsibility to educate all of its graduates about inequality and inspire them to take action to tackle inequity wherever they encounter it. As our honorary graduate Malala Yousafzai and passionate campaigner for education has said: "We should learn everything and then choose which path to follow" (Yousafzai, 2013). 


\section{Online references}

' http://www.edinburgh.gov.uk/news/article/2204/ edinburgh_is_british_entrepreneurial_city_of_ the year

${ }^{2}$ https://www.topuniversities.com/universityrankings

${ }^{3}$ http://www.scotsman.com/future-scotland/tech/ one-small-step-for-john-knox-one-giant-leap-foruniversity-1-1413074

${ }^{4} \mathrm{http}: / /$ www.cityofliterature.com/meet-peoplelibrary-cat/

${ }^{5}$ https://en.wikipedia.org/wiki/Edinburgh_Seven

${ }^{6} \mathrm{http}: / /$ www.ed.ac.uk/alumni/services/profiles

$7 \mathrm{http}: / /$ www.ed.ac.uk/equality-diversity/ celebrating-diversity/inspiring-women

${ }^{8} \mathrm{http} / / /$ www.ecu.ac.uk/equality-charters/athenaSWAN/

$9 \mathrm{http}: / /$ www.docs.csg.ed.ac.uk/EqualityDiversity/ Uni_Silver_2015.pdf

${ }^{10} \mathrm{http}: / /$ ourhistory.is.ed.ac.uk/index.php/First_ Woman_Professor,_1958

"http://www.ed.ac.uk/files/atoms/files/equal_ pay_audit_2017.pdf

${ }^{12}$ https://www.hesa.ac.uk/data-and-analysis/ publications/staff-2014-15/introduction

${ }^{13}$ https://www.ucu.org.uk/media/7959/ Holding-down-womens-pay-Feb-16/pdf/ucu IWDpayreport_mar16.pdf

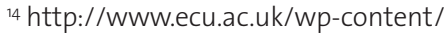
uploads/2015/11/Equality-in-HE-statistical-report2015-part-1-staff.pdf

${ }^{15} \mathrm{http}: / /$ www.docs.csg.ed.ac.uk/EqualityDiversity/ EDMARC_15_16/Staff_report.pdf

${ }^{16}$ http://www.ucu.org.uk/media/7959/ Holding-down-womens-pay-Feb-16/pdf/ucu_ IWDpayreport_mar16.pdf

${ }^{17} \mathrm{http}$ ://www.ed.ac.uk/equality-diversity/ monitoring-statistics/equal-pay-reports

${ }^{18} \mathrm{http}: / /$ www.docs.sasg.ed.ac.uk/gasp/factsheet/ StudentFactsheet310117.pdf
${ }^{19} \mathrm{http}: / /$ www.ecu.ac.uk/wp-content/ uploads/2015/11/Equality-in-HE-statistical-report2015-part-2-students.pdf

${ }^{20} \mathrm{http}: / /$ www.thestudentsurvey.com

${ }^{21}$ https://unistats.ac.uk/

${ }^{22} \mathrm{http}: / / w w w . e d . a c . u k / e q u a l i t y-d i v e r s i t y /$ innovation-development/athena-SWAN

${ }^{23} \mathrm{http}$ ///www.ed.ac.uk/easter-bush-campus/ where-people-thrive/campus-development/ campus-buildings/childcare-facilities

${ }^{24}$ https://www.eusa.ed.ac.uk/ eusapolicy/liberation/ improveuniversitysupportforstudentparents/

${ }^{25} \mathrm{http}: / /$ www.ed.ac.uk/information-services/ library-museum-gallery/using-library/join-thelibrary/policy-child-access

${ }^{26} \mathrm{https} / / /$ www.eusa.ed.ac.uk/eusapolicy/welfare/ genderneutral/

${ }^{27}$ https://www.eusa.ed.ac.uk/eusapolicy/ liberation/stoptakingthepiss/

${ }^{28} \mathrm{http}: / /$ www.ed.ac.uk/human-resources/ recruitment/talent-register

${ }^{29} \mathrm{http}$ ///www.ed.ac.uk/human-resources/ learning-development/mentoring-connections

${ }^{30} \mathrm{http}: / / w w w . e d . a c . u k / h u m a n-r e s o u r c e s /$ learning-development/dev-opportunities/a-zcourses/courses-a-l/aurora

${ }^{31}$ https://leanin.org/tips/mentorship]

${ }^{32} \mathrm{http}: / /$ www.ed.ac.uk/human-resources/learningdevelopment/dev-opportunities/leadershipdevelopment/coach-mentor/coaching

33 http://www.docs.csg.ed.ac.uk/HumanResources/ Policies/Shared_Parental_Leave_Policy_pdf

$34 \mathrm{http}: / / w w w . d o c s . c s g . e d . a c . u k / H u m a n R e s o u r c e s /$ Policies/Flexible\%2oWorking\%2oPolicy.pdf

$35 \mathrm{http}: / /$ www.ed.ac.uk/student-funding/financialsupport/students-children .

${ }^{36} \mathrm{http}: / /$ www.ed.ac.uk/files/atoms/files/ studentmaternitypolicy.pdf 